\title{
A Priority Based Course Planning System for Electrical Engineering Department
}

\author{
Mohammad S. Laghari
}

\begin{abstract}
To create successful students an effective academic advising and course planning program is necessitated. An academic advisor is a link between the student and the institution therefore good advising is critical to the long-term success of an institution. Course planning and advising are trivial processes to ensure students fulfill the degree requirements of an institution in an all-inclusive and structured way, and without encountering unnecessary delays. As experienced academic advisors are hard to find, therefore computer programs doing course planning and academic advising are becoming popular. The United Arab Emirates University is one such institution where students have faced problems due to lack of an appropriate advising system and experienced academic advisors. In this respect, a Priority Based Course Planning System (PBCPS) is devised. PBCPS software package is developed by using the JAVA programming language. The system helps and guide students in selecting appropriate courses for a specific semester. The outcome of the course selection of a subsequent semester is stored in a file to help in course registration.
\end{abstract}

Index Terms-Academic advising, course planning, Java, software system.

\section{INTRODUCTION}

The registration process at an academic institution typically including universities is primarily to determine which students select what courses, and for the main purpose of the administration and registration office to keep its records updated. The registration process enables the students to obtain the required and authorized association of the university as well as to attain their authorized benefits and privileges. It is common that students register for particular courses, or modules, and concomitantly the members of the teaching staff construct class lists, and offer other academic activities by using the information collected from students' registration.

Typical academic advising problems include chosen courses with time conflicts, missed out on essential courses specific for alternate semesters, chosen unnecessary electives, chosen too many courses with higher semester credits or too less courses in a specific semester, etc. Students in this category suffer with problems such as class expulsion after two or three weeks because of prerequisites requirement, delay graduation because of unnecessary additional courses, or drop a complete semester because of minimum number of courses requirement, suffer with heavy semester load because of too many courses, etc.

Manuscript received July 15, 2016; revised January 5, 2017.

M. S. Laghari is with the Department of Electrical Engineering, United Arab Emirates University, Al Ain, U.A.E. (e-mail: mslaghari@uaeu.ac.ae).
The devised PBCPS at the College of Engineering, UAE University, helps and guides students in planning appropriate courses suitable to register online with the University Registration System.

A typical advising session starts with the student using a flash derive to input information on the passed and the current registered courses. Alternatively, the students may create a list of the past and current semester courses through an online display menu. After inputting this course information, the student is advised to select suitable courses from another eligible course list for the next semester. This choice of selection is based on five priority fields that are appended to each course of the complete degree program.

Subsequently, the student with a shorter list of eligible courses can map the precise selection from four to seven courses into a 2-d timetable grid. The grid shows a visual 2-d selection of courses with respect to the offering time and day. This display helps students to select and alternate courses suitable to their needs according to specific time and day. The selection procedure is devised to show only course choice for the Spring semester of 2016, however, courses for the next succeeding semesters can be selected but without the grid layout visualization.

The paper describes complete operation of the Priority Based Course Planning System package, which includes course selection based on five priority fields, help menus, course tables, restrictions, etc.

\section{BACKGROUND LITERATURE}

The advising software at the Electrical Engineering Department, Texas Tech University featured a Graphical User Interface (GUI) that allowed students to choose only the courses for which they have appropriate prerequisites and co-requisites requirements. The program also offered rule-based advice to students regarding special circumstances that it spots. The software is designed for straightforward modification, without programming, to accommodate addition or deletion of courses, prerequisites, co-requisites, and rules [1].

A Student Advising Software (SAS) package similar to the investigation of this presented research was developed by using JAVA computer programming language. A manual procedure helps and guides students in selecting appropriate courses suitable for online registration with the Banner University Registration System. However, the software was developed for an old and phased out curriculum [2].

An improved version of the SAS was developed to better suit the student needs. The system has an improved GUI with more help menus [3]. 
A Student Auto Advising System (SAAS) software package was developed. It is an automated system based on old curriculum, with limited functionality and about a $20 \%$ error rate [4].

The Author developed an Electrical Engineering Course Planning System (EECPS). It is a manual system developed for a new curriculum [5].

An automated course planning system to show a typical plan for the next registering semester is devised by using the Python programming language with improved functionality and lesser error rate [6].

Another automated course advising system to show a complete typical plan is developed that includes prioritized course selection. However, the system suffers with a reported higher error rate because of an inappropriate priority field [7].

The academics at the Florida Atlantic University developed a similar web-based advising system that supplemented the conventional advising process. The system's goals included minimization of repetitive tasks performed by advisors, encouragement of students to adopt a proactive attitude towards advising, make advising-related information available to remote students in a single place, and minimize inconsistencies in the advising process [8].

A Bayesian Network model by using a data mining technique is developed for planning course registration and advising that predicts a sequence of courses to be registered by undergraduate students whose majors are computer science or engineering. Evaluation of the model showed that the predictive power of this model is not $100 \%$ accurate but acceptable [9].

A web-based system called e-Advisor is developed for individualized study planning and scheduling problem by utilizing multi-agent system approach and ontology-driven methodology. The investigation describes the various types of agents used in e-Advisor, the development of the ontologies and their applicability [10].

Two project management tools are designed to help the students complete their degree plan in an efficient way. The first tool provided a visualization map of course sequences that are customized for each student, making advising adjustments that will optimize the time to obtain the degree under a constrained set of resources. The second tool is to collect information from multiple students through several semesters and is used to identify bottlenecks in the curriculum [11].

An expert system using JESS (a JAVA based rule engine and scripting environment) is developed that allow students to seek quick responses to their queries regarding their plan of study and progress in the program. The rule-based expert system is customized to suit individual student's course planning [12].

An expert system solution to the course-advising problem is developed. Within this project, an expert system shell (VPExpert) was used to develop the Academic Counseling Expert system. The project illustrated how powerful and extremely useful expert systems can be developed to perform routine tasks [13].

Another development was completed at the Wylie College IT for software architectural development of a course registration system using the specifications created for the college requirements. The Software Architecture Document provides an architectural overview of the C-Registration System. The C-Registration System was initiated by Wylie College IT to support online course registration [14].

A web-based advising system is developed to solve a technology-based "last mile" problem by developing and evaluating a web-based decision support tool (the Online Advisor) that helps advisors and students make better use of an already present university student information system [15].

\section{THE PBCPS SofTWARE PACKAGE}

The Department of Electrical Engineering students take 147 credit hours to fulfill the B.Sc. degree requirements in the Electrical Engineering field. Typically, the students take from a minimum of nine to a maximum of twelve semesters to complete their degree requirements with an average course load of four to seven courses (12 to 18 credits) per semester. Table I shows the course load requirements of the EE degree program.

TABLE I: EE PROGRAM DEGREE REQUIREMENTS

\begin{tabular}{lc}
\hline \hline Requirements & $\begin{array}{c}\text { Credit } \\
\text { Hours }\end{array}$ \\
\hline General Education Requirements & 21 \\
College Requirements & 41 \\
Compulsory Specialization & 52 \\
Requirements & 12 \\
Elective Specialization Requirements & 15 \\
Industrial Training & $\underline{06}$ \\
Graduation Projects & 147 \\
\hline \hline
\end{tabular}

A usual student enters an ID and name to start a typical planning session. The student then selects all previously passed and current semester courses.

Fig. 1 describes the way priority fields are associated with a specific course of the EE degree program. Five prioritized fields are appended to each course of the program to signify the importance of which course needs are to be selected in which specific semester or time.

Compulsory courses 'ELEC 335 - Digital Logic Design' and ELEC 345 - Digital Logic Design Lab. serve as an example to describe the association of the priority fields. These two courses open a total of five courses in the next two hierarchal levels including two technical electives.

Priority Field-1: specifies whether the course is a requirement for Industrial Training (IT). Industrial Training typically happens when a student has completed from 93 to 100 credits. Students gain training in an appropriate industry of their choice for one complete semester. The training semester is scheduled such that a suitable number of courses is left including the two Graduation Projects for the final two semesters after the training phase.

Although, ELEC 335 (Digital Logic Design) is not directly needed for IT however, another course (ELEC 451) in the forward hierarchal path is an IT requirement course as shown in the Fig. 1.

Priority Field-2: indicates the number of forward hierarchal 
levels. Courses with longer hierarchal paths or levels are not missed by the students otherwise it may delay the training phase or even the graduation.

Courses with a higher field-2 value are therefore prioritized to be taken earlier. The Digital Logic Design course has a single path with two hierarchal levels in this path that include ELEC 451 / ELEC 461 (the laboratory course for ELEC 451), and ELEC 462.

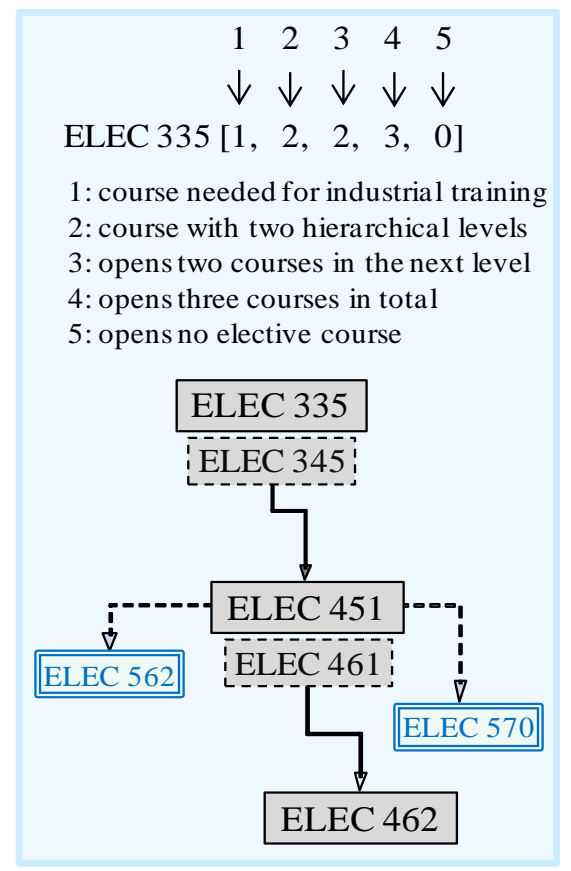

Fig. 1. Description of priority levels.

Priority Field-3: indicates the number of course openings in the next level. Higher number of courses opening in the next semester is prioritized over the courses with less number. For the specified course, there are two courses in the next level: ELEC 451 and ELEC 461.

Priority Field-4: indicates the number of courses in all hierarchal paths and priority levels. The ELEC 335 course opens three courses in its single path as shown in Fig. 1.

Priority Field-5: indicates the number of technical electives that can be opened by this course. There are no technical electives dependent on this course.

Fig. 2 shows all program courses including the prerequisite/co-requisite requirements (arrow directions), technical electives, the industrial training course ELEC 495, and the two-graduation project courses of ELEC 585 \& ELEC 590.

Similar to the above mentioned course example, all EE courses are appended with the five priority fields based on the hierarchal chart of Fig. 2 and are shown in Table II.

For example, course ELEC 360 - Signals \& Systems, appended with $(1,2,3,5,1)$ specifies that the course is required for the IT, the course has two hierarchal levels of ECOM 360 and ELEC 432 / ELEC 442, opens three courses in the immediate two hierarchal levels of ECOM 360 and ELEC 431 / ELEC 433, overall opens five courses in all paths and levels, and lastly opens one technical elective of ELEC 551.

The priority fields are prioritized with field-1 having the highest priority and field- 5 the least. All courses with a larger numeric value in field- 1 are considered before other fields are investigated. After field-1, a higher value in field-2 is considered for course selection process. Similarly, other lower priority fields are considered if course selection decision cannot be taken with the higher priority fields.

Table III shows a list of all technical electives. Students typically take these in their final two semesters. All priority fields' values for electives are zeros as shown in the Table.

The priority fields are associated with the technical elective courses only to show consistency with other courses and if an elective course becomes eligible earlier in the student's plan then it is the student's choice to either select it or leave it to register later typically after the industrial training semester and specifically in last two semesters.

\section{TEST CASES}

Four test cases are investigated. The package procedures are described with respect to Test Case 1.

\section{A. Test Case 1}

The software package is designed with a multiple and selectable three windows to select passed courses, to select courses for the Spring 2016 semester and to display selected courses in a 2-D timetable, respectively.

The course selection of the previously passed and current semester is saved into a file and an array and passed to the next phase of the package. This course selection from the previous phase is used to create an array of all remaining courses that are required by a typical student to complete the degree requirements.

The system then automatically downloads another file that contains all (general education, college specific, compulsory requirements, elective, etc.) courses offered in the next investigating semester (Spring 2016). The program ultimately creates a shorter list of courses based on eliminating all courses offered in the Spring 2016 semester whose prerequisites have not been taken by the student.

The system displays this shorter list of courses in a multiple selection list form for the student to select appropriate courses based on the information displayed according to the priority fields. The course selection is displayed in the 2-d grid format (time and day) for the student to decide on the most appropriate from four to seven courses for the Spring 2016 semester.

List of earned including the current semester courses are shown following for the first example. The courses are shown with color-coding with college requirement courses (blue color), university requirements (red color), department (black color), industrial training and graduation projects (green color), and technical electives (light blue color).

\section{List of earned courses: \\ CHEM_111, CHEM_175, PHYS_1110, MATH_1110, GENG_200, GENG_250, STAT_220, MATH_1120, PHYS_1120, GENG_220, ESPU_107, MATH_2220, GENG_315, ELEC_305, ELEC_310, ELEC_325, ELEC_335, ELEC_345, MATH_2210, ITBP_119.}

\section{Earned Credits: 53 \\ Required Credits: 94}




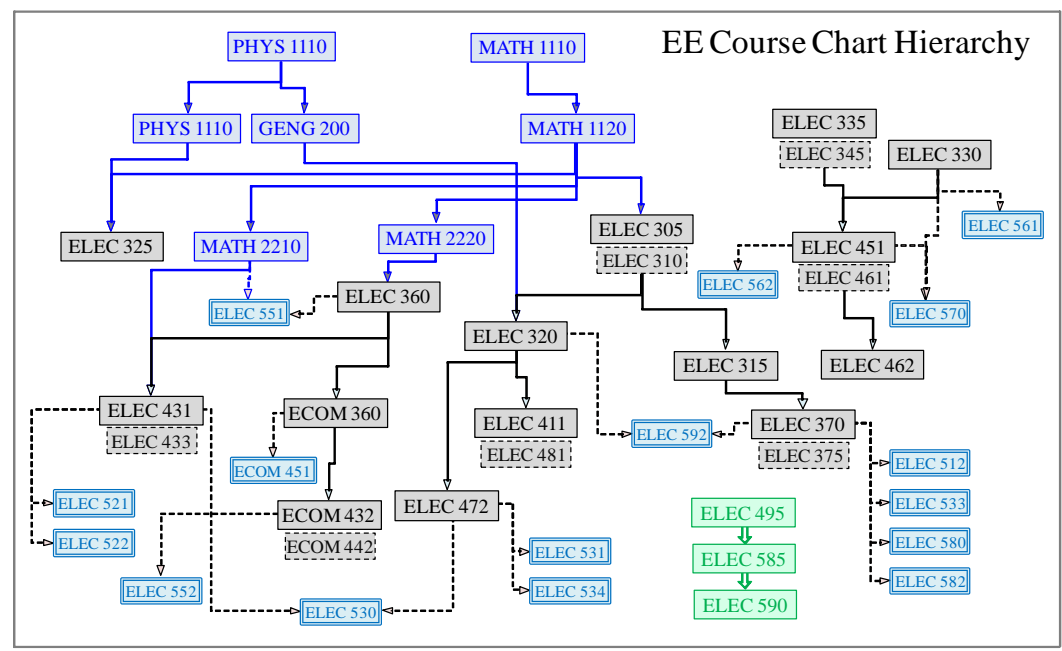

Fig. 2. Hierarchical chart of EE course structure.

TABLE II: CORE COURSES WITH PRIORITY LEVELS

\begin{tabular}{|c|c|c|c|c|c|c|c|}
\hline Core Courses & Cr. & Course Code & 1 & 2 & 3 & 4 & 5 \\
\hline Emirates Society & 3 & HSS 105 & 0 & 0 & 0 & 0 & 0 \\
\hline Islamic Thoughts & 3 & ISLM 1103 & 0 & 0 & 0 & 0 & 0 \\
\hline English for Engineering & 3 & ESPU 107 & 1 & 1 & 1 & 1 & 0 \\
\hline ESP 2 for Engineering & 3 & ESPU 1452 & 1 & 0 & 0 & 0 & 0 \\
\hline Gen. Cult. Hum. \& Soc. Sciences 1 & 3 & GCH\&SS1 & 0 & 0 & 0 & 0 & 0 \\
\hline Gen. Cult. Hum. \& Soc. Sciences 2 & 3 & GCH\&SS2 & 0 & 0 & 0 & 0 & 0 \\
\hline Gen. Cult. Hum. \& Soc. Sciences 3 & 3 & GCH\&SS3 & 0 & 0 & 0 & 0 & 0 \\
\hline Freshman Lab & 2 & GENG 250 & 1 & 0 & 0 & 0 & 0 \\
\hline Engineering Statistics & 2 & STAT 220 & 1 & 0 & 0 & 0 & 0 \\
\hline Introduction to Programming & 2 & GENG 200 & 1 & 3 & 1 & 4 & 0 \\
\hline Engineering Ethics & 2 & GENG 215 & 1 & 0 & 0 & 0 & 0 \\
\hline Engineering Thermodynamics & 3 & GENG 220 & 1 & 2 & 1 & 4 & 0 \\
\hline Calculus I for Engineers & 3 & MATH 1110 & 1 & 5 & 3 & 21 & 0 \\
\hline Calculus II for Engineers & 3 & MATH 1120 & 1 & 4 & 5 & 18 & 0 \\
\hline Differential Equations \& Engineering Applications & 3 & MATH 2210 & 1 & 3 & 1 & 6 & 0 \\
\hline Linear Algebra \& Engineering Applications & 3 & MATH 2220 & 1 & 1 & 2 & 2 & 1 \\
\hline Physics \& Engineering Applications I & 4 & PHYS 1110 & 1 & 3 & 2 & 7 & 0 \\
\hline Physics \& Eng. Applications II & 4 & PHYS 1120 & 1 & 1 & 1 & 1 & 0 \\
\hline General Chemistry I & 3 & CHEM 111 & 1 & 1 & 1 & 1 & 0 \\
\hline Chemistry Lab I for Engineering & 1 & CHEM 175 & 1 & 1 & 1 & 1 & 0 \\
\hline Engineering Practice \& Entrepreneurship & 3 & GENG 315 & 1 & 0 & 0 & 0 & 0 \\
\hline Materials Science & 3 & CHEM 2706 & 1 & 0 & 0 & 0 & 0 \\
\hline Electric Circuits I & 3 & ELEC 305 & 1 & 2 & 2 & 7 & 0 \\
\hline Electric Circuits I Lab & 1 & ELEC 310 & 1 & 2 & 2 & 7 & 0 \\
\hline Fundamentals of Microelectronic Devices & 3 & ELEC 315 & 1 & 1 & 2 & 2 & 0 \\
\hline Electric Circuits II & 3 & ELEC 320 & 1 & 1 & 3 & 3 & 0 \\
\hline Engineering Electromagnetics & 3 & ELEC 325 & 1 & 0 & 0 & 0 & 0 \\
\hline Computer Programming & 3 & ELEC 330 & 1 & 2 & 2 & 3 & 2 \\
\hline Digital Logic Design & 3 & ELEC 335 & 1 & 2 & 2 & 3 & 0 \\
\hline Digital Logic Design Lab & 1 & ELEC 345 & 1 & 2 & 2 & 3 & 0 \\
\hline Signals \& Systems & 3 & ELEC 360 & 1 & 2 & 3 & 5 & 1 \\
\hline Fundamentals of Communication Systems & 3 & ECOM 360 & 1 & 1 & 2 & 2 & 1 \\
\hline Electronic Circuits & 3 & ELEC 370 & 1 & 0 & 0 & 0 & 5 \\
\hline Electronic Circuits Lab & 1 & ELEC 375 & 1 & 0 & 0 & 0 & 5 \\
\hline
\end{tabular}




\begin{tabular}{|l|c|l|c|c|c|c|c|}
\hline Electric Energy Conversion & 3 & ELEC 411 & 0 & 0 & 0 & 0 & 0 \\
\hline Control Systems & 3 & ELEC 431 & 0 & 0 & 0 & 0 & 3 \\
\hline Data Communications \& Networks & 3 & ECOM 432 & 0 & 0 & 0 & 0 & 1 \\
\hline Instrumentation \& Control Lab & 1 & ELEC 433 & 0 & 0 & 0 & 0 & 3 \\
\hline Data Communications \& Networks Lab & 1 & ECOM 442 & 0 & 0 & 0 & 0 & 1 \\
\hline Microprocessors & 3 & ELEC 451 & 1 & 1 & 1 & 1 & 2 \\
\hline Microprocessors Lab & 1 & ELEC 461 & 1 & 1 & 1 & 1 & 2 \\
\hline Computer Architecture and Organization & 3 & ELEC 462 & 0 & 0 & 0 & 0 & 0 \\
\hline Power Systems & 3 & ELEC 472 & 0 & 0 & 0 & 0 & 3 \\
\hline Electric Energy Conversion Lab & 1 & ELEC 481 & 0 & 0 & 0 & 0 & 0 \\
\hline Industrial Training & 15 & ELEC 495 & 0 & 2 & 1 & 2 & 0 \\
\hline Graduation Project I & 3 & ELEC 585 & 0 & 1 & 1 & 1 & 0 \\
\hline Graduation Project II & 3 & ELEC 590 & 0 & 0 & 0 & 0 & 0 \\
\hline
\end{tabular}

\begin{tabular}{|c|c|c|c|c|c|c|c|}
\hline Elective Courses & Cr. & Course Code & 1 & 2 & 3 & 4 & 5 \\
\hline Digital Signal Processing & 3 & ECOM 451 & 0 & 0 & 0 & 0 & 0 \\
\hline Digital Electronics & 3 & ELEC 512 & 0 & 0 & 0 & 0 & 0 \\
\hline Advanced Control Systems & 3 & ELEC 521 & 0 & 0 & 0 & 0 & 0 \\
\hline Industrial Automation & 3 & ELEC 522 & 0 & 0 & 0 & 0 & 0 \\
\hline Special Topics in Power \& Control & 3 & ELEC 530 & 0 & 0 & 0 & 0 & 0 \\
\hline Power System Analysis & 3 & ELEC 531 & 0 & 0 & 0 & 0 & 0 \\
\hline Very Large Scale Integration & 3 & ELEC 533 & 0 & 0 & 0 & 0 & 0 \\
\hline Power System Distribution & 3 & ELEC 534 & 0 & 0 & 0 & 0 & 0 \\
\hline Digital Image Processing & 3 & ELEC 551 & 0 & 0 & 0 & 0 & 0 \\
\hline Computer Networks & 3 & ELEC 552 & 0 & 0 & 0 & 0 & 0 \\
\hline Java Programming Applications & 3 & ELEC 561 & 0 & 0 & 0 & 0 & 0 \\
\hline Embedded System Design & 3 & ELEC 562 & 0 & 0 & 0 & 0 & 0 \\
\hline Special Topics in Computer Engineering & 3 & ELEC 570 & 0 & 0 & 0 & 0 & 0 \\
\hline Special Topics in Electronic Engineering & 3 & ELEC 580 & 0 & 0 & 0 & 0 & 0 \\
\hline Analog Integrated Circuit Design & 3 & ELEC 582 & 0 & 0 & 0 & 0 & 0 \\
\hline Power Electronics & 3 & ELEC 592 & 0 & 0 & 0 & 0 & 0 \\
\hline
\end{tabular}

Proposed Courses for Spring 2016

HSS_105

$0,0,0,0$

ISLM_1103

0,0

GCH\&SS2

0,0

GCH\&SS3

0,0

ESPU_1452

0,0

GENG_215

$0,0 \checkmark$

CHEM_2706

$0,0 \checkmark$

ELEC_330

$3,2 \checkmark$

ELEC_315

$2,0 \checkmark$

ELEC_320

$3,0 \checkmark$

ELEC_360

$5,1 \checkmark$
Emirates Studies

Islamic Thoughts

G. Cult. Hum. \& Soc. Sc. $2 \quad 0,0,0$,

G. Cult. Hum. \& Soc. Sc. 3

$0,0,0$,

ESP 2 for Engineering

$0,0,0$,

Engineering Ethics

Materials Science

Computer Programming

Fund. Microelectronic Dev.

Electric Circuits II

Signals \& Systems
This typical student has 53 earned credits. From the list of 0 , 40 courses offered in Spring 2016 semester, the student only finds 11 courses suitable for course selection. This selection choice is made easier with a ' 1 ' in the priority field- 1 to select six courses (17 credits).

\section{B. Test Case 2}

\section{List of earned courses:}

HSS_105, ISLM_1103, ESPU_107, GENG_200, PHYS_1110,

$1,0,0$, MATH_1110,CHEM_111, CHEM_175, ESPU_1452, GENG_250, MATH_1120,STAT_220, ELEC_305, ELEC_310, GENG_220,

1, 0, 0, MATH_2210, GENG_315, ELEC_320, ELEC_335, ELEC_345, ELEC_360, PHYS_1120, MATH_2220.

\section{Earned Credits: 62}

Required Credits: 85

1, 1, 3, Proposed Courses for Spring 2016
GCH\&SS1
G. Cult. Hum. \& Soc. Sc. 1 ,

$1,2,3, \quad 0,0,0,0$

$\mathrm{GCH} \& \mathrm{SS} 2$

$0,0,0,0$
G. Cult. Hum. \& Soc. Sc. $2 \quad 0$, 


\begin{tabular}{|c|c|c|c|c|c|}
\hline $\begin{array}{l}\text { GCH\&SS3 } \\
0,0,0,0\end{array}$ & G. Cult. Hum. \& Soc. Sc. 3 & 0 , & $\begin{array}{l}\text { HSS_105 } \\
0,0,0,0\end{array}$ & Emirates Studies & 0 \\
\hline GENG_215 & \multirow[t]{2}{*}{ Engineering Ethics } & \multirow[t]{2}{*}{1 , } & GCH\&SS3 & \multirow[t]{2}{*}{ G. Cult. Hum. \& Soc. Sc. 3} & \multirow[t]{2}{*}{$0,0,0$} \\
\hline $0,0,0,0 \checkmark$ & & & 0,0 & & \\
\hline $\begin{array}{l}\text { CHEM_2706 } \\
0,0,0,0 \checkmark\end{array}$ & Materials Science & 1 , & $\begin{array}{l}\text { GENG_215 } \\
0,0\end{array}$ & Engineering Ethics & $1,0,0$, \\
\hline $\begin{array}{l}\text { ELEC_330 } \\
2,2,3,2 \checkmark\end{array}$ & Computer Programming & 1 , & $\begin{array}{l}\text { CHEM_2706 } \\
0,0\end{array}$ & Materials Science & $1,0,0$, \\
\hline $\begin{array}{l}\text { ELEC_315 } \\
1,2,2,0 \checkmark\end{array}$ & Fund. Microelectronic Dev. & 1 , & $\begin{array}{l}\text { MATH_2210 } \\
6,0 \checkmark\end{array}$ & Diff. Equ. \& Engg. Appl. & $1,3,1$, \\
\hline $\begin{array}{l}\text { ELEC_325 } \\
0,0,0,0 \checkmark\end{array}$ & Engg. Electromagnetics & 1 , & $\begin{array}{l}\text { MATH_2220 } \\
2,1\end{array}$ & \multicolumn{2}{|c|}{ Linear Algebra \& Engg Appl. 1, 1, 2, } \\
\hline \multirow{2}{*}{\multicolumn{2}{|c|}{$1,2,2,1 \checkmark$}} & & $\begin{array}{l}\text { ELEC_305 } \\
7,0 \checkmark\end{array}$ & Electric Circuits I & $1,2,2$, \\
\hline & & & ELEC_310 & Electric Circuits I Lab & $1,2,2$, \\
\hline \multirow{2}{*}{\multicolumn{3}{|c|}{$\begin{array}{l}\text { Similar to the first Test Case, again the selection choice for } \\
\text { this typical student is straightforward. From the course } \\
\text { eligible list, all (six) courses with a ' } 1 \text { ' in first field are } \\
\text { selected to complete } 17 \text { credit hours for the next semester. }\end{array}$}} & $\begin{array}{l}7,0 \checkmark \\
\text { ELEC_325 }\end{array}$ & Engg. Electromagnetics & $1,0,0$, \\
\hline & & & $\begin{array}{l}0,0 \\
\text { ELEC_330 } \\
3,2 \checkmark\end{array}$ & Computer Programming & $1,2,2$, \\
\hline \multicolumn{3}{|c|}{ C. Test Case 3} & $\begin{array}{l}\text { ELEC_335 } \\
3,0 \checkmark\end{array}$ & Digital Logic Design & $1,2,2$, \\
\hline \multicolumn{3}{|c|}{ ISLM_1103, HSS_105, ESPU_107, GENG_200, MATH_1110, } & $\begin{array}{l}\text { ELEC_345 } \\
3,0 \checkmark\end{array}$ & Digital Logic Design Lab & $1,2,2$, \\
\hline
\end{tabular}

STAT_220, GENG_220, GENG_215, ARGB 360, GENG_250, MATH_1120, PHYS_1120, ELEC_325, ELEC_330, ELEC_335, ELEC_345, ESPU_1452, MATH_2210, MATH_2220.

\section{Earned Credits: 66 \\ Required Credits: 81}

\section{Proposed Courses for Spring 2016}

\begin{tabular}{llr}
\hline GENG_315 & Engg. Practice \& Entre. & $1,0,0$, \\
$0,0 \checkmark$ & Materials Science & $1,0,0$, \\
CHEM_2706 & & \\
$0,0 \checkmark$ & Electric Circuits I & $1,2,2$, \\
ELEC_305 & & \\
$7,0 \checkmark$ & Electric Circuits I Lab & $1,2,2$, \\
ELEC_310 & & \\
$7,0 \checkmark$ & Signals \& Systems & $1,2,3$, \\
ELEC_360 & & \\
$5,1 \checkmark$ & Microprocessors & $1,1,1$, \\
ELEC_451 & & \\
$1,2 \checkmark$ & Microprocessors Lab & $1,1,1$, \\
ELEC_461 & & \\
$1,2 \checkmark$ & Sp. Top. in Computer Engg. & $0,0,0$, \\
ELEC_570 & &
\end{tabular}

This typical student has only one technical elective course left as an alternative. The student's choice from the system is only eight courses with a selection of seven courses that includes two course Labs with 1-credit each totaling to 17 semester credit hours.

\section{Test Case 4}

\section{List of earned courses:}

ISLM 1103, ESPU_107, HSR 220, MATH_1110, GENG_200, PHYS_1110, ESPU_1452, CHEM_111, CHEM_175, ARCH_346, GENG_250, MATH_1120,STAT_220, ENG_315, GENG_220, PHYS_1120.

\section{Earned Credits: 45 \\ Required Credits: 102}

Proposed Courses for Spring 2016
In Test Case 4, the student has to choose from 12 courses. Again, the student selection choice is clearly indicated from field-2. All courses with a '2' and higher are chosen from this field. Six courses with 14 credit hours are chosen for the Spring 2016 semester.

\section{CONCLUSION}

Course planning and advising are trivial processes to ensure that students fulfill the degree requirements of an institution in an all-inclusive and structured way, without encountering any unnecessary delays. A Priority Based Course Planning System (PBCPS) is devised in this respect. The system helps and guides students in selecting appropriate courses suitable to register online with the University Registration System. Four Test Cases are investigated to show near optimum course selection results.

\section{REFERENCES}

[1] M. Hagler, "Stand-alone PC-based advising aid for students," Frontiers in Education Conference Proceedings, pp. 3a3.18-3a3.21, vol. 1, 1995.

[2] M. S. Laghari, Q. A. Memon, and Habib-ur-Rehman, "Advising for course registration: a UAE University perspective," presented at the International Conference on Engineering Education, Gliwice, Poland, July 25-29, 2005.

[3] M. S. Laghari and G. A. Khuwaja, "Electrical engineering department advising for course planning," presented at the IEEE Global Engineering Conference, Marrakech, Morocco, April 17-20, 2012.

[4] M. S. Laghari and G. A. Khuwaja, "Course advising \& planning for electrical engineering department," WJEIS, vol. 2, pp. 172-181, 2012

[5] M. S. Laghari, "Electrical engineering course planning system," presented at the $8^{\text {th }}$ International Conference on Engineering and Technology Research, Dubai, April 24-25, 2014.

[6] M. S. Laghari, S. A. Al Habsi, N. A. Maaz, and M. A. A. Al Naqbi, "A one-semester course planner for EE students," presented at the $2^{\text {nd }}$ International Research Conference on Engineering, Science and Management, Dubai, June 3-4, 2015.

[7] M. S. Laghari, “Automated course advising system," IJMLC, vol. 4, pp. 47-51, 2014.

[8] O. Marques, X. Ding, and S. Hsu, "Design and development of a web-based academic advising system," The $31^{\text {st }}$ ASEE/IEEE Frontiers 
in Education Conference Proceedings, pp. S3C-6-S3C-10, vol. 3, 2001.

[9] P. Pumpuang, A. Srivihok, P. Praneetpolgrang, and S. Numprasertchai, "Using bayesian network for planning course registration model for undergraduate students," presented at the $2^{\text {nd }}$ IEEE International Conference on Digital Ecosystems and Technologies, Phitsanulok, Thailand, February 26-29, 2008.

[10] F. Lin, S. Leung, D. Wen, F. Zhang, and M. Kinshuk, "E-advisor: A multi-agent system for academic advising," presented at the Workshop on Agent-Based Systems for Human Learning and Entertainment (ABSHLE) at Autonomous Agents and Multi-Agent Systems (AAMAS), Honolulu, Hawaii, May 14-18, 2007.

[11] V. Gonzalez and D. Esparza, "Work in progress-advising tool to improve the time for graduation and the transfer of students from a community college to engineering school," presented at the $40^{\text {th }}$ ASEE/IEEE Frontiers in Education, Washington DC, October 27-30, 2010.

[12] A. N. Nambiar and A. K. Dutta, "Expert system for student advising using JESS," presented at the International Conference on Educational and Information Technology, San Francisco, October 20-22, 2010.

[13] M. Patankar, "A rule-based expert system approach to academic advising," Innovations in Education and Training International, vol. 35, pp. 49-58, 1998.
[14] S. Johnson, "Software architecture document for course registration system version 1.0," A Technical Report: Wylie College IT, 1999.

[15] T. Feghali, I. Zbib, and S. Hallal, "A web-based decision support tool for academic advising," Journal of Educational Technology \& Society, vol. 14, pp. 89-94, 2011.

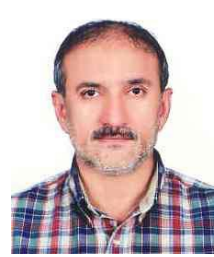

Mohammad S. Laghari received his B.E. degree in electronic engineering from Mehran University of Engineering and Technology, Jamshoro, Pakistan, the M.S. degree in electrical engineering from Drexel University, Philadelphia, Pennsylvania, U.S.A., and the $\mathrm{Ph} . \mathrm{D}$. in computer engineering from the University of Wales, Swansea, Wales, U.K. in 1980, 1983, and 1993, respectively.

He has worked as an assistant professor at Kuwait and King Saud Universities, and is currently an associate professor at the Department of Electrical Engineering, United Arab Emirates University, Al Ain, U.A.E. His research interests are in applied artificial intelligence, image processing, pattern recognition, and software systems. He has published more than 85 papers in these areas.

Dr. Laghari is a member of the IACSIT (Singapore), PEC (Pakistan), UACEE (USA), and IRED (USA). 